\title{
Tribological tests of the improved piston mechanism of the axial piston hydraulic machine
}

\author{
S Stazhkov', A Kuzmin ${ }^{1,2}$, V Elchinskiy ${ }^{1}$ and N Yakovenko ${ }^{1}$ \\ ${ }^{1}$ Baltic State Technical University "VOENMEH”, 1, First Krasnoarmeyskaya str, \\ Saint-Petersburg, 190005, Russia \\ E-mail: ${ }^{2}$ wutmakat@yandex.ru
}

\begin{abstract}
Axial-piston hydraulic swash plate machines are widely applied in positive displacement hydraulic drives of various purposes. Such drives are highly energy-intensive and have a relatively small control range due to the presence of a large dead-band, which limits their use in reverse action systems. To reduce the dead-band, an improved axial-piston hydraulic swash plate machine was designed. The decrease of the dead-band is achieved by reducing the friction forces in the piston mechanism. This article presents the results of comparative tribological tests of a standard and improved piston mechanisms. The experimental research was conducted in terms of reducing the friction forces in the piston mechanism and their effect on the moment of starting of the hydraulic machine. It was revealed that the use of the improved piston mechanism allows to increase the useful force of the piston up to $20 \%$ in the motor mode and to reduce the dead band by 1.6 times when switching to the pump mode.
\end{abstract}

\section{Introduction}

Axial-piston hydraulic swash plate machines are used in hydraulic drives, which have high requirements for energy consumption and fast response. These hydraulic machines are distinguished by their weight and dimensions characteristics, simplicity of assembly and manufacturability in comparison with axial-piston hydraulic bent-axis machines. However, the disadvantage of swash plate machines is a relatively large dead-band and, as a result, a relatively small control range.

The breakaway and transition to a stable mode of operating speed change in swash plate machines, even at idling, comes at $70 \ldots 100 \mathrm{rad} / \mathrm{s}$, while in the best examples of bent-axis machines it comes at $3 \ldots 5 \mathrm{rad} / \mathrm{s}$. Therefore, swash plate machines have a significantly lower control range compared to bent-axis machines.

These facts take place due to the features of the design scheme of these hydraulic machines. The tilt angle of the cylinder block in modern bent-axis machines reaches 45 degrees due to the connection between the drive flange and the cylinder barrel, provided by pistons. In swash plate machines, due to the presence of large transverse forces acting on the piston and as a result of high friction forces in the 'piston-cylinder' pair, the tilt angle of the swash plate, as a rule, does not exceed 20 degrees.

This leads to the fact that the force produced by the piston in the bent-axis machine in comparison with the swash plate machine is converted into a much larger torque. One of the ways to reduce the dead zone of the swash plate machine is to reduce friction forces in the piston pair. 
There are modern researches that are focused on the problem of the piston mechanism of the swash plate machine [1]-[4]. However, these works describe operating at a high speed, therefore, excluding the problem of the dead-band and moment of starting.

This article presents the results of testing of improved piston mechanism on a test rig using the principles of inversion of the movement of this type of hydraulic machines units and energy recovery [5].

The improved piston [6] mechanism has a bearing displacement relative to the longitudinal axis of the piston, which allows to change the power scheme of the transverse forces and significantly reduce the total reaction, and, consequently, a value of the friction forces in the piston pair.

In addition, the displacement of the bearing allows hydrostatic bearing of the 'piston-cylinder' pair application.

This article presents the results of comparative tests of a standard piston mechanism, an improved piston mechanism with a displaced bearing without hydrostatic bearing of the piston pair, and an improved piston mechanism with a displaced bearing and hydrostatic bearing of the piston pair.

\section{Test in the motor mode}

For tests in the motor mode, a working fluid was pumped into the piston chamber, under pressure from the pumping station. The piston acted on the rotating wash plate, which, in turn, through the lever acted on the force sensor. This allowed to determine the moments of breakaway for standard and improved piston mechanisms at different pressure levels in the piston chamber, which corresponds to different levels of loading of the hydraulic machine, as well as to determine the reduction of friction forces in the researched piston pairs. The initial data for series of experiments is presented in table 1.

Table 1. Experiment initial data and conditions

\begin{tabular}{cc}
\hline Slipper - outer edge of the bushing distance, $\mathrm{mm}$ & $16.4-45.6$ \\
Piston diameter, $\mathrm{mm}$ & 20.614 \\
Working fluid temperature range, ${ }^{\circ} \mathrm{C}$ & $20-35$ \\
$\quad$ Swash plate tilt angle, ${ }^{\circ}$ & 18 \\
$\quad \begin{array}{c}\text { guiding bushing axis, mm } \\
\text { Distance between the rotation axis of the cylinder block and the }\end{array}$ & 45 \\
piston axis, mm & 11.83 \\
\hline
\end{tabular}

As the result of the tests, the reduction in the friction forces was obtained when using the improved piston mechanisms in comparison with the standard one.

The force value on the sensor is converted to the axial force value according to the following dependence:

$$
F_{A X}=F_{S} \cdot l /\left(R_{C} \cdot \tan 18^{\circ}\right)
$$

$F_{A X}$ - force, applied from the piston to the swash plate in axial direction, $F_{S}$ - force, registered by the sensor, $l$ - lever length, $R_{C}$ - distance between the swash plate rotation axis and the guiding bushing axis. The friction forces reduction can be found using the following formula:

$$
F_{F R}=F_{P}^{I M}-F_{P}^{S}
$$

$F_{P}{ }^{I M}$ - axial force of the improved piston mechanism, $F_{P}{ }^{I M}$ - axial force of the standard piston mechanism

The results of the experiment are presented in the figure 1 . 


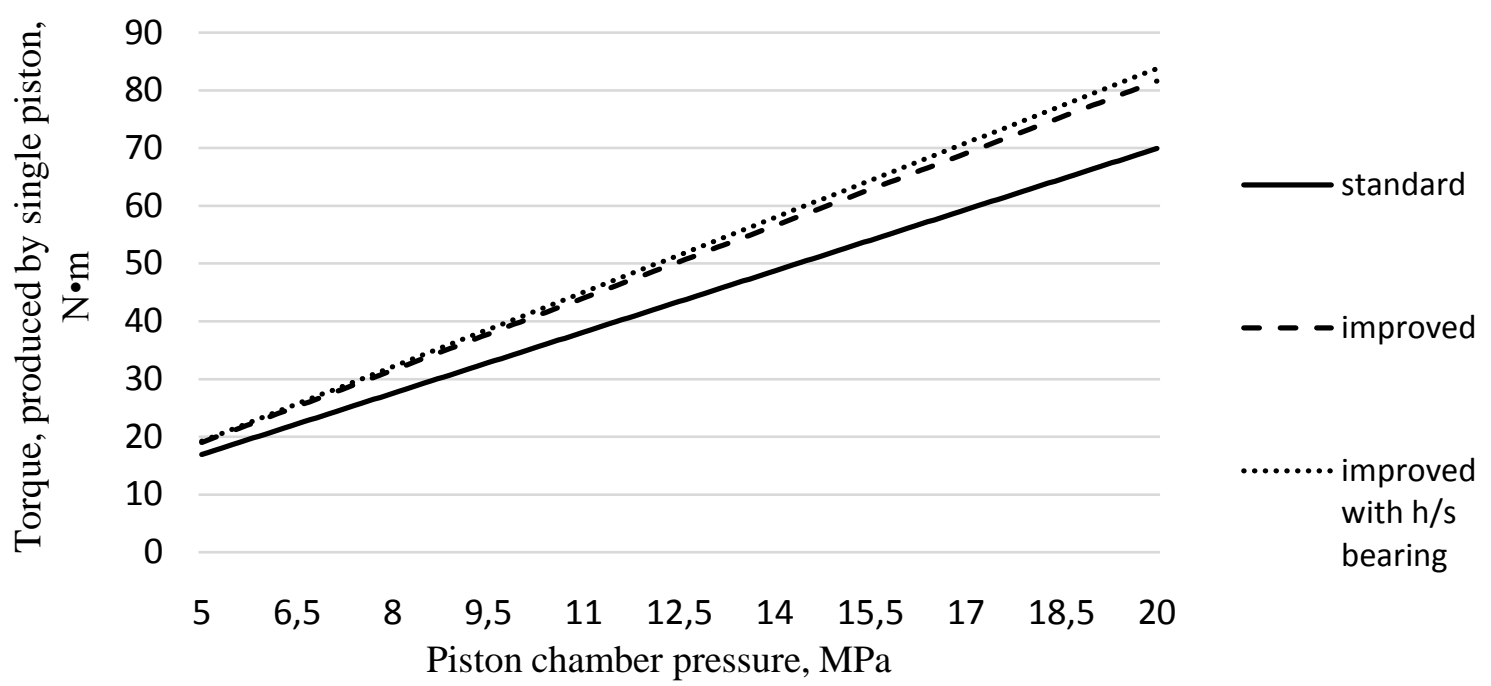

Figure 1. Dependence of the shaft torque produced by a single piston on the pressure in the piston chamber for the piston mechanism of standard design, modified design and modified design with hydrostatic bearing.

Calculations results are shown in the Figure 2.

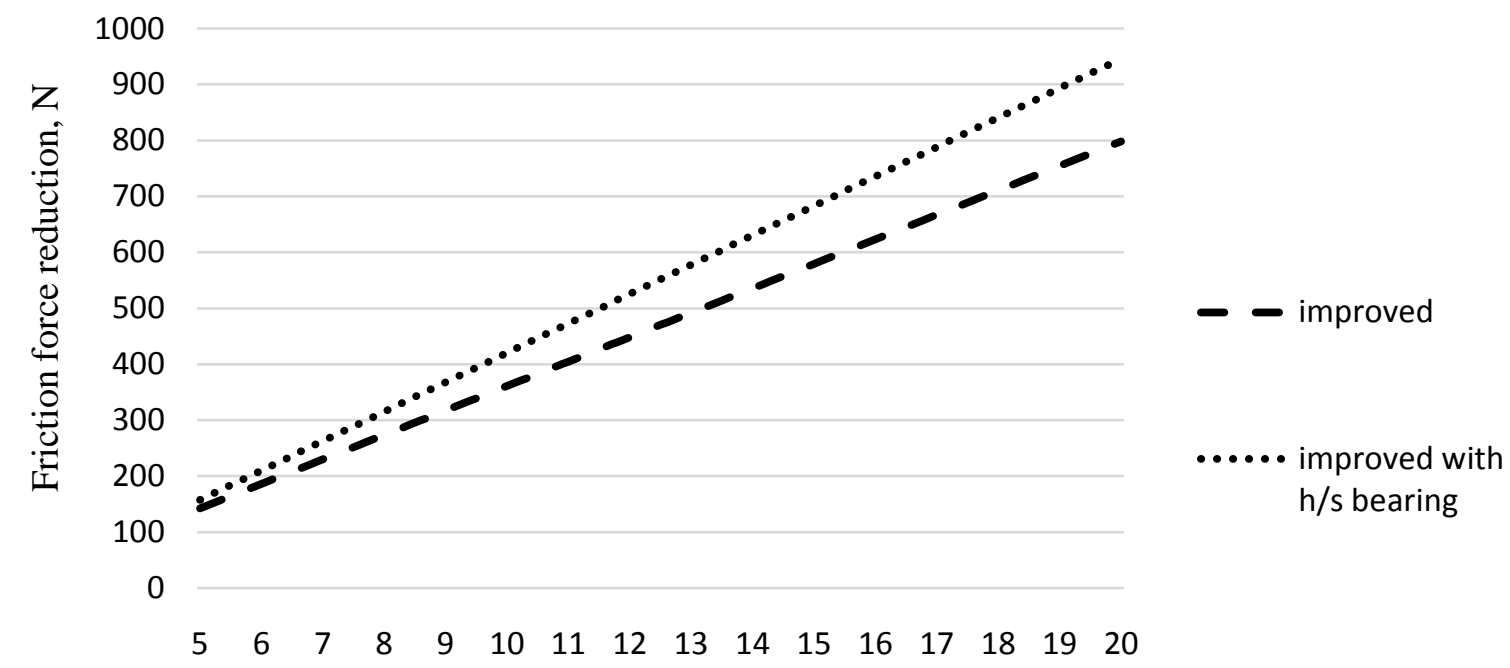

Piston chamber pressure, $\mathrm{MPa}$

Figure 2. Reduction of the axial component of the friction forces in the motor mode for the improved piston and for the improved piston with hydrostatic bearing in comparison with the standard design piston.

\section{Tests in the pump mode}

To determine the friction forces in the pump mode, as well as to determine the range of the dead zone when switching to the pump mode of the hydraulic machine, a series of experiments were conducted.

On a lever of $0.3 \mathrm{~m}$ in length, a calibrated weight of $13 \mathrm{~kg}$ and $17 \mathrm{~kg}$ was alternately installed, which corresponded to the torque on the shaft of 38.3 and $50 \mathrm{~N} \cdot \mathrm{m}$. The pressure in the piston chamber gradually decreased from the value allowing to keep the load on the weight, to the value at which the lever together with a support disk was moving from their seats. In this way, the piston mechanism was 
switched to the pump mode of operation. The moment of switching to the pump mode was registered using the force sensor simultaneously with the pressure sensor.

According to the results obtained, dependences of changes in the friction forces in the piston pairs in the pump mode for the tested piston mechanisms were constructed. The friction force was defined as the difference between the calculated value of the pressure at which the corresponding load should be balanced, and the actual value obtained during the experiment, multiplied by the area of the end of the piston. The obtained results are shown in Figure 3.

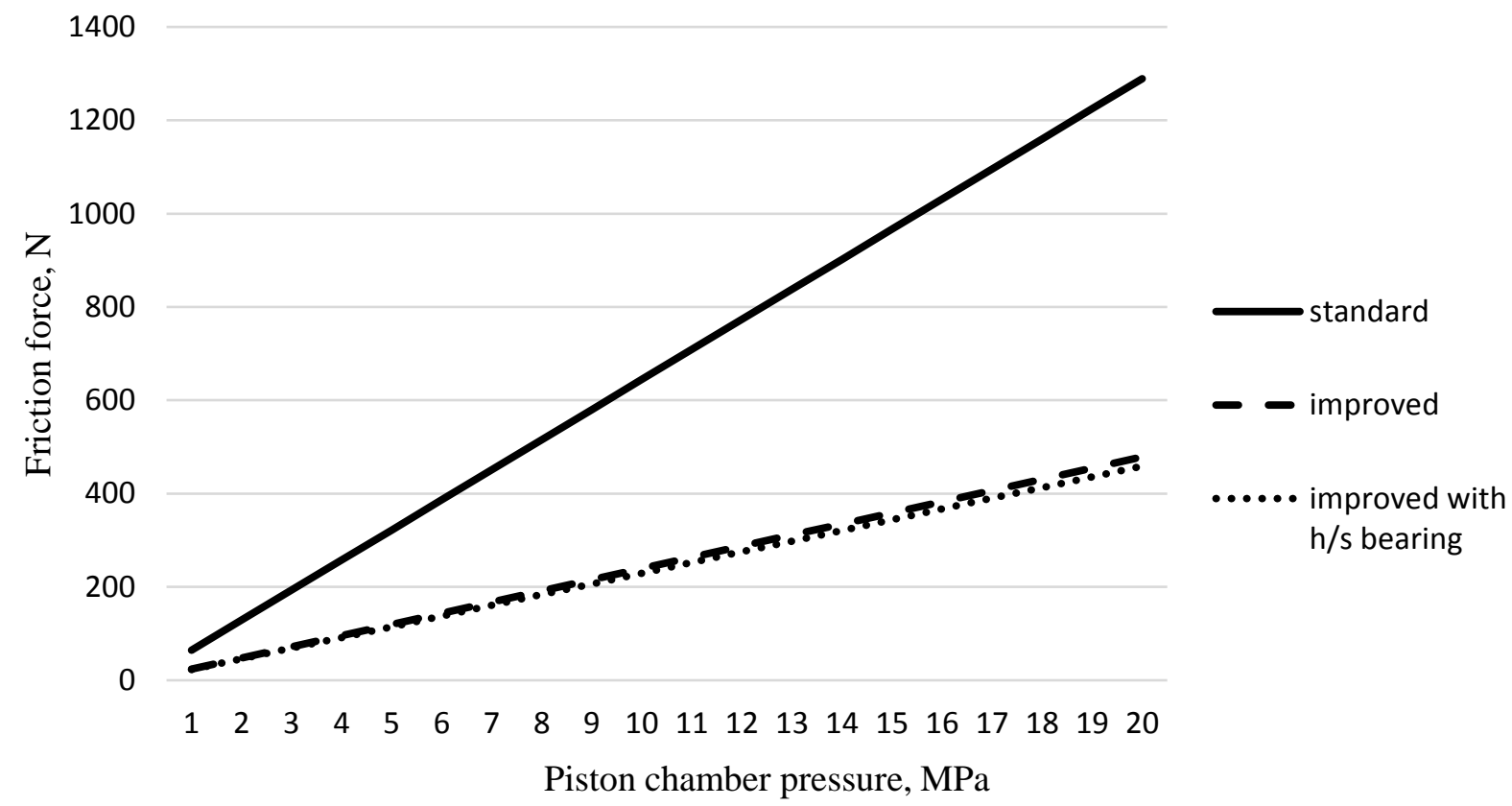

Figure 3. Dependence of the friction force in the piston pair on the pressure for the standard, improved and improved with hydrostatic bearing of piston mechanisms in the pump mode.

\section{Results and conclusion}

Experimental studies have shown:

- the use of the improved piston mechanism reduces the friction forces in the motor mode by $798 \mathrm{~N}$ at the piston chamber pressure value of $20 \mathrm{MPa}$, which leads to an increase in the useful force produced by the piston mechanism by $16.7 \%$;

- the use of the improved piston mechanism with hydrostatic bearing reduces the friction forces in the motor mode by $941 \mathrm{~N}$ at the piston chamber pressure value of $20 \mathrm{MPa}$, which leads to an increase in the useful force produced by the piston mechanism by $20 \%$;

- the use of the improved piston mechanism allowed to reduce the dead band by 1.6 times when switching to the pump mode and reduce the friction forces by 2.6 times at the shaft torque of $50 \mathrm{~N} \cdot \mathrm{m}$;

- the use of the improved piston mechanism with hydrostatic bearing allowed to reduce the dead band by 1.6 times when switching to the pump mode and reduce friction forces by 2.8 times at the shaft torque of $50 \mathrm{~N} \cdot \mathrm{m}$.

The results of the presented experiments lead to assume that the use of the improved piston mechanism in axial-piston swash plate hydraulic machines will significantly expand the use of these hydraulic machines in reverse drives.

\section{References}

[1] Matteo Pelosi and Monika Ivantysynova 2012 A Geometric Multigrid Solver for the PistonCylinder Interface of Axial Piston Machines Tribology Transactions 55:2, pp 163-174, DOI: 
10.1080/10402004.2011.639049

[2] Li F, Wang D, Lv Q, Haidak G and Zheng S 2019 Prediction on the lubrication and leakage performance of the piston-cylinder interface for axial piston pumps. Proceedings of the Institution of Mechanical Engineers, Part C: Journal of Mechanical Engineering Science 233(16) pp 5887-96 doi 10.1177/0954406219851150

[3] Jiang J and K Wang 2015 An integrated model of hydrodynamic lubricating for piston/cylinder interface, International Conference on Fluid Power and Mechatronics (FPM) (Harbin) pp 47-52 doi: 10.1109/FPM.2015.7337083

[4] Xu B, Zhang J, Yang H and Zhang B 2013 Investigation on the Radial Micro-Motion about Piston of Axial Piston Pump. Chinese Journal of Mechanical Engineering 26 (2) pp 325-33

[5] Kuzmin A, Popov V and Stazhkov S 2016 Advanced Axial Piston Swash Plate Pump Parameters Recommendations Proceedings of the 27th DAAAM International Symposium doi 10.2507/27th.daaam.proceedings.082

[6] Stazhkov S, Korobova I, Korolev V and Kuzmin A 2019 Hydrodynamic Processes Research of the Positive Displacement Hydraulic Machines Piston Interface Proceedings of the 30th DAAAM International Symposium pp 0580-5 doi 10.2507/30th.daaam.proceedings.078 